\title{
AERODYNAMIC CHARACTERISTICS OF A STRAIGHT WING WITH A SPIROID WINGTIP DEVICE
}

\author{
Igor F. Kravchenko ${ }^{1}$ (D) 0000-0003-2304-3356 \\ Vasyl V. Loginov ${ }^{*}$ (DD 0000-0003-4915-7407 \\ Yevgene O. Ukrainets ${ }^{3}$ (D) 0000-0002-7674-0588 \\ Pavlo A. Hlushchenko ${ }^{3}$ (i) 0000-0002-8231-8877 \\ ${ }^{1}$ SE Ivchenko-Progress, 2, Ivanova Str., Zaporozhye, Ukraine, 69068 \\ 2 JSC FED, 32, Sumska Str., Kharkiv, Ukraine, 61023 \\ ${ }^{3}$ Ivan Kozhedub National Air Force University, 77/79, Sumska Str., Kharkiv, Ukraine, 61023 \\ *login_w@ukr.net
}

\begin{abstract}
Spiroid wingtip devices (WD) offer a promising way of improving the lift drag ratio of UAVs, but may on the other hand lead to negative aerodynamic interference of the wing with the WD and deterioration of the aerodynamic characteristics as compared to a wing without the WD. Determining the influence of the geometric parameters of a spiroid WD on aerodynamic wing characteristics, however, remains an understudied field. In our study, we investigated the influence of the following geometrical parameters on wing aerodynamic characteristics with WD: area, radius, camber angle, constriction, and pitch of the spiroid. We found that the positive effect of the WD is present at a relative radius $\bar{r}>0.05$, as well as with an increase in the lift coefficient $C_{L}$ as a result of an increase in the proportion of inductive resistance. For example, with the Reynolds number $\mathrm{Re}=2.1 \times 10^{5}$ for a rectangular wing with an aspect ratio $\theta=5.12$ equipped with a spiroid WD with $\bar{r}=0.15$ the quality gain is almost $10 \%$ at $C_{L}=0.5$, and at $C_{L}=0.7$ is almost $20 \%$ and at $C_{L}=0.7-$ almost $20 \%$ compared to a wing without WD. Moreover, we found that a change in the camber angle WD $\theta$ provides an increase in the derivative of the lift coefficient with respect to the angle of attack in the range from $\theta=0^{\circ}$ to $\theta=130^{\circ}$. By changing the camber angle, it is possible to increase the lift drag ratio of the layout up to $7.5 \%$ at $\theta=90^{\circ}$ compared to $\theta=0^{\circ}$ at the Reynolds number $\operatorname{Re}=2.1 \times 10^{5}$. From the point of view of ensuring maximum lift drag ratio and minimum inductive drag, the angle $\theta=90^{\circ}$ is the most beneficial.
\end{abstract}

Keywords: lift drag ratio, flight range, flight duration, unmanned aerial vehicles, aerodynamic configuration, spiroid wingtip devices

Type of the work: Research Article 


\section{INTRODUCTION}

The relative simplicity and significantly lower costs of production, maintenance and operation of unmanned aerial vehicles (UAVs) as compared to manned aerial vehicles has contributed to the proliferation of UAVs to perform tasks in various fields of activity, such as monitoring of the Earth's surface. The use of UAVs for surface monitoring provides a variety of advantages over other monitoring tools: high resolution of surface surveying due to low flight altitudes, efficient receiving and processing of information, environmental safety, etc. [1]. In fact, the effectiveness of surface monitoring depends on the range and duration of the UAV flight, thus giving rise to demand for UAVs to ensure increased flight range and duration. Optimal flight modes that provide maximum flight range and duration generally depend on the aerodynamic and mass characteristics of an aircraft, as well as on the characteristics of its propulsion [2]. However, to assess the efficiency of aerodynamic layouts, compare and pre-select the main parameters of the layout, it is sufficient to limit the impact on the target functions (flight range and duration) only to aerodynamic characteristics, highlighting partial criteria of optimality [2]. These criteria are selected depending on the type of aircraft and taking into account the tasks to be performed. One of the aerodynamic criteria that particularly affects an UAV's flight range and duration is its lift drag ratio. For UAVs with a propeller-driven group, the value of the maximum lift drag ratio $K_{\max }$ provides the maximum flight range, and the criterion $K \sqrt{C_{L}}$ value is the maximum flight duration [2]. Therefore, one of the urgent tasks when designing a UAV for surface monitoring is achieving high values of the lift drag ratio [3].

One of the common ways to improve the lift drag ratio is increasing the wing aspect ratio. In this case, air and inertial loads acting on a large aspect ratio wing cause an increase in its deformations, bending moment in the wing root sections and wing deflections, and a decrease in wing stiffness causes noticeable changes in local angles of attack, distributed and integral aerodynamic characteristics [4]. In total, this leads to persistent and unstable oscillations with different cycles that can reduce the resource of the structure [5, p. 9]. A possible alternative way of increasing the wing aspect ratio is the use of a WD on the wing. WD application is possible on existing and prospective UAVs and leads to a decreased final flows and changes in the intensity and structure of final vortices. This reduces the inductive drag and increases the wing bearing properties, and improves the lift drag ratio of the UAV airframe in general. However, WD application entails an increase of the washed area, and the need to ensure positive aerodynamic interference of the wing and the WD [6]. Thus, it is necessary to determine the influence of the WD's geometrical parameters on the wing's aerodynamic characteristics, which will make it possible to make a rational choice of the optimal geometric parameters of the wing and the WD. The values of these parameters should ensure the maximum value of the selected aerodynamic criterion: lift drag ratio. Therefore, determining the influence of the WD geometric parameters on the wing aerodynamic characteristics is an urgent scientific and practical task.

\section{LITERATURE DATA ANALYSIS AND PROBLEM STATEMENT}

A large number of WDs exist [7], the most common ones including Whitcomb winglets, shark winglets, Split Scimitar winglets, etc. However, a particularly promising design is the spiroid WD (spiroid loop) [8], the concept of which Gratzer filed in a patent [9] in 1992 and is installed on a prototype aircraft Falcon 50. Spiroids form an annular or rectangular closed surface (Fig. 1) [10]. 


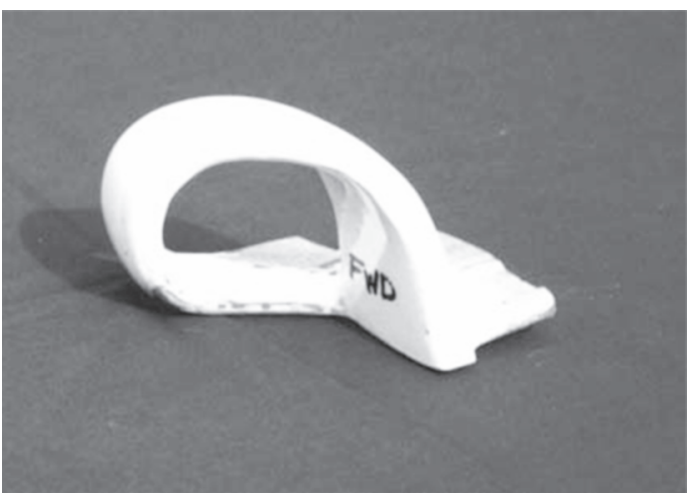

a) FWD spiroid

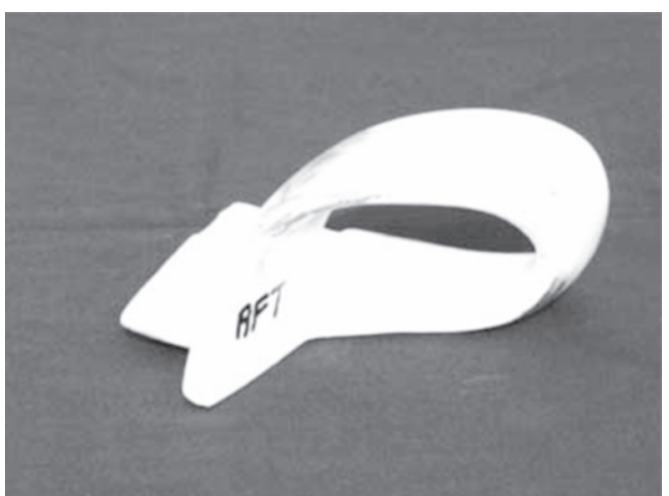

b) AWT spiroid

Fig. 1. Spiroids types [10].

There are 2 types of spiroids: FWD (Forward Spiroid Winglet - directed forward along the air flow) (Fig. 1a) and AFT (Aft Spiroid Winglet - directed backwards along the air flow) (Fig. 1b). Initial tests of the spiroid WD were carried out on a Gulfstream II aircraft, with a reduction in fuel consumption of more than 10\% [7]. A numerical study of the influence of spiroid WD geometric parameters on the lift drag ratio, range and flight duration of a Falcon 50 aircraft was carried out in [11]. Multiparameter dependence of the aerodynamic characteristics on the geometric parameters of the spiroid WD is shown, namely, on the shape of the spiroid (cylindrical, rectangular, semi-cylindrical, parallelogram), the shape, profile thickness and twist of the spiroid walls, geometric dimensions and the striation angle of the spiroid. According to the results of parametric studies [12] for the Falcon 50 aircraft, spiroid WDs were chosen which provide the minimum inductive resistance. A comparison was also made of the range and duration of the aircraft's flight with various types of WD and without WD. For an aircraft with a wing without WD, the maximum flight range was $6480 \mathrm{~km}$, for an aircraft with traditional WDs, it was $6847 \mathrm{~km}$, and for an aircraft with a spiroid WD, it was $7863 \mathrm{~km}$, the maximum flight duration being $6.45 \mathrm{~h}, 6.82 \mathrm{~h}$, $7.83 \mathrm{~h}$, respectively. At the same time, the researchers found it impossible to determine the influence of spiroid WD on the distributed and moment characteristics of the wings, or to establish other dependences of aerodynamic characteristics on the geometric parameters of the WD. In [12] numerical modeling was carried out on the basis of the ANSYS Fluent software package for Boeing 777 aircraft wing with a spiroid and traditional WD. It was shown that at an angle of attack of $4^{\circ}$, spiroid WDs have a greater decrease in inductive resistance $(-5 \%)$ and an increase in the lift coefficient by $1.5 \%$. For the Boeing 737 wing [13], with the installation of spiroid WDs, the lift drag ratio was increased from 5.388 to 5.7 units, which amounted to $5.7 \%$.

In theoretical $[10,11]$ and experimental studies [11], significant differences in the distribution of the field of velocities and pressures behind the wing, the flow structure when using spiroid WD were shown when compared with other types of WD and wings without WD. A special feature is that several final vortices are formed behind the spiroids of the WD. The intensity of the indicated vortices behind the spiroid WD rapidly decreases, as well as their short lifetime and the distance to their decay in comparison with other WD types. Analysis of works [7-14] allows us to conclude that the features of the application of spiroid WD, especially when used on UAVs at various values of the Reynolds number, have not been sufficiently studied. Other works devoted to the application of WD are reviewed in [15], with a brief description of the research methods and parameters employed, the effect on the aerodynamic characteristics of which was determined by the given quantitative estimate.

Thus, the publications in the existing literature are aimed at identifying the wing aerodynamic characteristics with WD for large aircraft, the aerodynamics of which differ from the aerodynamics 
of UAVs. An essential feature and disadvantage of spiroid WD as applied to mainline aircraft is the appearance of transonic effects earlier than on the main wing [16]. At lower Reynolds and Mach numbers, this effect is absent. For other conditions of wing-spiroid WD layouts, the dependences of the distributed and total aerodynamic characteristics on the geometric parameters of the WD have not been published in the available sources of scientific and technical information. Thus, the study of the influence of spiroid WD geometric parameters on the aerodynamic characteristics of wings with WD is highly relevant.

\section{STUDY PURPOSE AND OBJECTIVES}

The aim of the study, therefore, is to determine the dependences of the aerodynamic characteristics of a wing with spiroid WD on the geometric parameters of the WD. Partial objectives are as follows:

- determining the influence of the camber angle of the spiroid WD on the aerodynamic characteristics of the wing with WD;

- determining the influence of the area and radius of the spiroid on the aerodynamic characteristics of the wing with WD;

- determining of the influence of the step and taper ratio of the spiroid on the aerodynamic characteristics of the wing with WD.

\section{METHOD OF DETERMINING WING AERODYNAMIC CHARACTERISTICS WITH A FINITE AERODYNAMIC SURFACE}

The process of flow around the surface of bodies is modeled by experimental and theoretical methods of aerodynamics. The method of determining aerodynamic characteristics is based on the idea of dividing aerodynamic forces into components, depending on the nature of their occurrence. Aerodynamic characteristics, which depend on the pressure forces, are determined by numerous methods for solving the Euler equations via the modified discrete vortex method. Aerodynamic characteristics, which depend on the friction forces, are determined by a semi-empirical model, which is based on the processing of experimental data and the theory of the boundary layer. To ensure the reliability of the results obtained by theoretical methods, such models are tested in a wind tunnel. This approach maximizes the advantages and minimizes the disadvantages of each of the individual methods, so as to provide an acceptable level of material and time costs; obtain reliable results; determine the characteristics of layouts for which there are no statistical dependencies; and correct the theoretical model by comparison with wind tunnel tests.

To determine the aerodynamic characteristics which are caused by the pressure forces, we considered the problem of a continuous stationary (if necessary, unsteady) flow around a wing with finite aerodynamic surfaces by a subsonic incompressible flow of an inviscid fluid. The flow is considered potential everywhere, with the exception of the wing and WD surfaces, as well as the vortex sheet (Fig. 2). The locations of vortex sheet descent are considered known a priori and fixed. The coordinates of points in space at a given moment of time $t$ (at a dimensionless moment of time $\tau$ ) are set by the radius vector $r(x, y, z)$, or in a dimensionless form $\bar{r}(\bar{x}, \bar{y}, \bar{z})$, referred to the average aerodynamic chord.

In this case, there is a potential $\partial \varphi(t, \bar{r})$ that satisfies the Laplace equation [17]:

$$
\frac{\partial^{2} \varphi(t, \bar{r})}{\partial x^{2}}+\frac{\partial^{2} \varphi(t, \bar{r})}{\partial y^{2}}+\frac{\partial^{2} \varphi(t, \bar{r})}{\partial z^{2}}=0 .
$$


Then the pressure field $p(t, \bar{r})$ at an arbitrary point in space is determined by the Cauchy-Lagrange integral for the Euler equations of motion [17]:

$$
p(t, \bar{r})=p_{\infty}-\rho\left(\frac{\partial \varphi(t, \bar{r})}{\partial t}+\frac{1}{2} \bar{v}^{2}(r, \bar{r})\right)
$$

where $p_{\infty}-$ flow pressure, $\bar{v}(\tau, \bar{r})$ - perturbed velocity.

The total aerodynamic force is determined by integrating the pressure over the body surface [17]:

$$
\bar{R}=-\int_{S_{T}} p\left(t, \bar{r}_{s}\right) \bar{n}\left(t, \bar{r}_{s}\right) d S_{T}
$$

where $\bar{n}\left(t, \bar{r}_{s}\right)$ - unit vector of the outer normal to $S_{T}$.

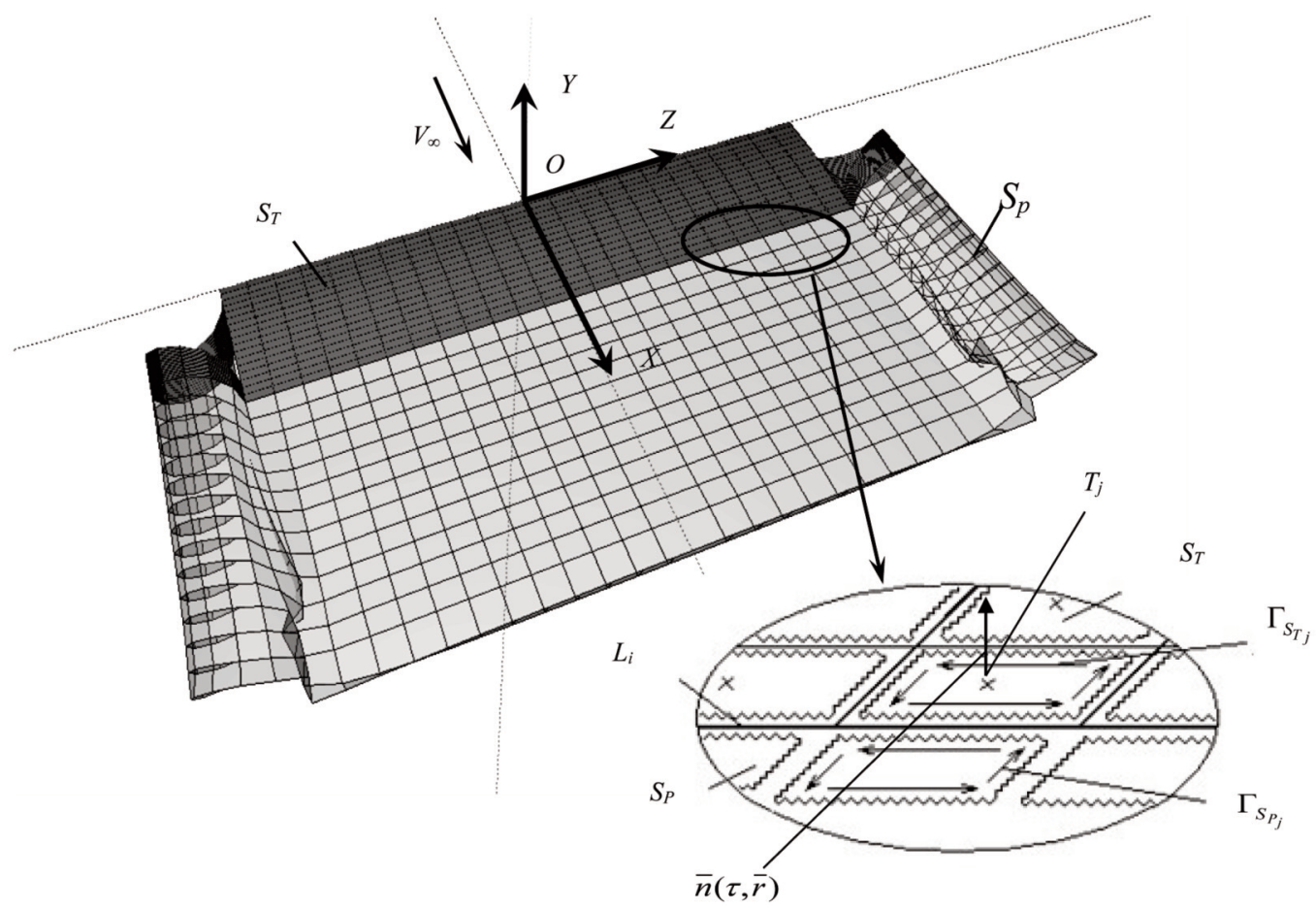

Fig. 2. Design scheme of the flow around the layout model of the wing - WD

Thus, the solution to the flow problem is to determine the velocity potential that satisfies the Laplace equation and the boundary conditions. These are: [18]:

- no leakage on the body surface $S_{T}$ :

$\frac{\partial \varphi(\tau, \bar{r})}{\partial n}=-\bar{V}_{\infty} \cdot \bar{n}(\tau, \bar{r})$ 
- continuity of the normal component of velocity and pressure on the upper $(+)$ and lower $(-)$ surfaces of the vortex sheet $S_{I I}$ :

$(\nabla \varphi(\tau, \bar{r}) \cdot \bar{n}(\tau, \bar{r}))_{+}=(\nabla \varphi(\tau, \bar{r}) \cdot \bar{n}(\tau, \bar{r}))_{-}, p_{+}=p_{-}$

- damping of disturbances at infinite distance from the body:

$\lim _{x \rightarrow \infty} \nabla \varphi-0$

- equality of pressures and finiteness of velocities on the trailing edges of the surfaces $L_{i}$ from which the vortex sheet rises:

$p_{+}=p_{-}$.

The numerical solution of the flow problem when using a modified discrete vortex method proceeds by replacing the continuous surface of the body, which is approximated by an infinitely thin surface, and the continuous vortex sheets by discrete ones modeled by closed vortex frames with constant circulation $\Gamma$ around the perimeter. This ensures the hydrodynamic closure of the vortex system. The surface of the body and the vortex sheet is divided into elements (panels) (Fig. 2).

Satisfying the boundary conditions $(4-7)$ at the collocation points (centers of panels) [18], we obtain a system of equations for the unknown value of the potential jump:

$\varphi(\tau, \bar{r})=\frac{1}{4 \pi}\left(\sum_{j=1}^{N_{S_{T}}} \theta_{S_{T_{j}}}(\tau, \bar{r}) \Gamma_{S_{T_{j}}}(\tau)+\sum_{k=1}^{N_{S_{I I}}} \theta_{S_{P_{k}}}(\tau, \bar{r}) \Gamma_{S_{P_{k}}}\right)$,

where the coefficients $\theta_{S_{T_{j}}}(\tau, \bar{r})$ and $\theta_{S_{P_{k}}}(\tau, \bar{r})$ are the solid angle at which the panel is seen from the point $\bar{r} ; \Gamma_{S_{T_{j}}}(\tau)$ and $\Gamma_{S_{P_{j}}}$ are dimensionless circulations of $j$ and $k$ vortex frame of the body and the vortex sheet, respectively.

To determine the pressure field in the modified discrete vortex method, a direct calculation of the perturbed velocity $\bar{v}(\tau, \bar{r})$ is performed, which leads to a system of equations for the unknown value of the perturbed velocity:

$\bar{v}(\tau, \bar{r})=\frac{1}{4 \pi}\left(\sum_{j=1}^{N_{S_{T}}} \bar{w}_{S_{T_{j}}}(\tau, \bar{r}) \Gamma_{S_{T_{j}}}(\tau)+\sum_{k=1}^{N_{S_{P}}} \bar{w}_{S_{P_{k}}}(\tau, \bar{r}) \Gamma_{S_{P_{k}}}\right)$,

where $\bar{w}_{S_{T_{j}}}(\tau, \bar{r})$ and $\bar{w}_{S_{P_{k}}}(\tau, \bar{r})$ are the velocities induced by the vortex frame of the body and the sheet, respectively. To calculate the field of velocities from vortex frames, the Bio-Savart formula [18 is used. An algorithm for determining the velocity field, velocity potential and aerodynamic force coefficients by the discrete vortex method is given [18].

The components of the models' profile resistance was determined by the calculation method carried out on the basis of a semi-empirical model. The components of the profile drag are due to the participatory and normal aerodynamic forces. The tangential components arise from the air viscosity and are due to the frictional resistance. The normal components arise as a result of a change in the pressure distribution over the body surface in a real flow around the body as compared to the distribution of pressure in 
a continuous and stationary flow of an ideal fluid around the body. The change in the pressure distribution over the body surface is due to the influence of viscosity and the displacing action of the boundary layer and determines the pressure resistance, which together with the frictional resistance constitutes the profile resistance of the body.

According to the experimental data, the profile resistance in a continuous flow is almost independent of the angle of attack [19]. Some increase occurs only at critical angles of attack due to an increase in the thickness of the boundary layer and the appearance of shear zones. Therefore, the drag coefficient can be determined as follows:

$C_{D}=C_{D_{0}}+C_{D_{i}}$

where $C_{D_{0}}$ is drag coefficient at zero lift, $C_{D_{i}}$ is inductive drag coefficient.

At a subsonic flight speed in the absence of resistances from various sources, one can write [19]:

$C_{D_{0}}=C_{D p}=2 C_{f} \eta_{c}$

where $C_{D p}$ is the coefficient of the model profile resistance; $C_{f}$ is the coefficient of the flat plate frictional drag in an incompressible fluid flow at the same Reynolds number and the transition point position of laminar flow into turbulent flow with a given wing; the doubled value takes into account the friction with the lower and upper surfaces; and $\eta_{c}$ is the coefficient that takes into account the contribution of pressure resistance to profile resistance.

The friction coefficient of a thin plate is calculated according to the following relationship [19]:

$C_{f}=\frac{0.087}{(\lg \operatorname{Re}-1.6)^{2}}\left(1-\bar{x}_{T}\right)+\frac{1.33}{\sqrt{\operatorname{Re}}} \sqrt{\bar{x}_{T}}$,

where $\bar{x}_{T}$ is the relative coordinate of the transition point position, and the Re number is calculated from the characteristic size (wing chord) and for certain flight conditions.

Since different Reynolds numbers can be realized in a real UAV flight, then crisis phenomena and cutting changes in the wing's aerodynamic characteristics are possible, which are not taken into account by the semi-empirical model, the wing models were tested in the T- 1 wind tunnel at the Ivan Kozhedub National Air Force University in Kharkiv. When significant differences were revealed between theoretical and experimental values, we proposed to use the experimental data as a basis and to correct the theoretical model. When determining the aerodynamic characteristics of the models, the weighting method and the method of lost impulses were used $[20,21]$. To obtain a qualitative picture of the flow around the models, the methods of visualization of currents were used: the tuft method and the smoke method (Fig. 3). Parameters and flow characteristics of the closed wind tunnel with an open test section are given in [22], whereas a description of the experimental procedure and the introduction of corrections are given in [23].

The wing models were made of wood by gluing the parts together, the spiroid WD models of $3 \mathrm{~mm}$ thick plastic. The surface of the models was painted, varnished and polished with a cotton disc with Forecla G10 polish. The 'wing - WD' layout model had three hardpoints on the underside of the wing. The Reynolds number during the tests was fixed at $\operatorname{Re}=2.1 \times 10^{5}$. 


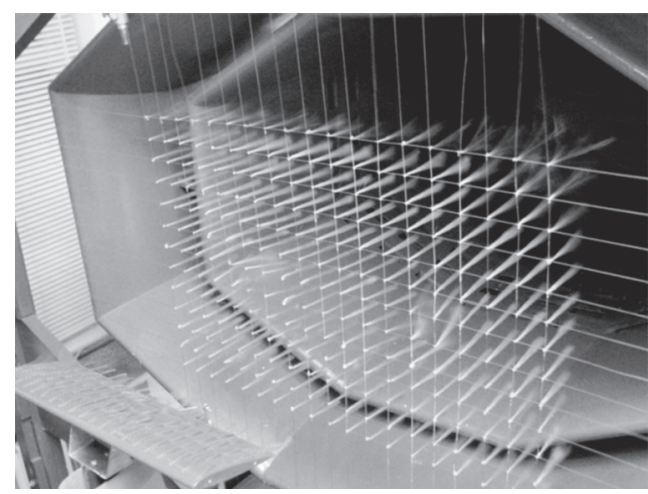

a) without WD

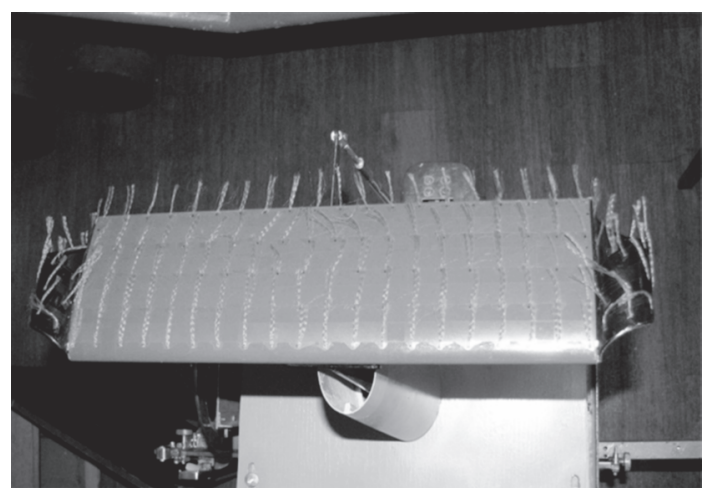

b) with spiroid WD

Fig. 3. Wing models with and without WD in the test section of the T-1 wind tunnel during visualizations of the flow around the models.

\section{AERODYNAMIC CHARACTERISTICS OF WINGS WITH SPIROID WD}

WD application and the resulting change in geometric parameters leads to a change in the true angle of attack of the wing sections, especially in the wing final part, which leads to a change in circulation, distributed and total aerodynamic characteristics. We investigated the influence of the following geometrical parameters of spiroid WD: area and radius of spiroid, constriction, pitch and camber angle of WD.

One of the most important parameters of the layout is the WD camber angle (Fig. 4), which can significantly influence the interference. We investigated the influence of the camber angle on the total characteristics of the 'wing - WD' layout. The wing model with aspect ratio $\lambda=5.12$ is rectangular in plan, with wing chord $b_{w}=0.13 \mathrm{~m}$, wingspan $l=0.65 \mathrm{~m}$, wing area $\mathrm{S}_{\mathrm{w}}=0.0845 \mathrm{~m}^{2}$. The spiroid WD is a thin plate with chord $b_{\mathrm{WD}}=b_{w} / 2$, spiroid radius $r=0.45 \mathrm{~m}$, taper ratio $\eta_{\mathrm{WD}}=1$.

The WD camber angle significantly affects the distribution of lift, as a result of changes in the position of the final vortices. This causes a flow different slope and causes changes in the distribution of lift over the wingspan depending on $\theta$, which leads to a change in the integral characteristics. To compare the change in integral characteristics, the dependences of the lift drag ratio $K$ and the aerodynamic criterion $K \sqrt{C_{L}}$ on the camber angle $\theta$ are shown (Fig. 5). The values of the maxima $K$ and $K \sqrt{C_{L}}$ are close, and their surroundings are flat, which will satisfy the requirements for increasing both the range and duration of the flight.

Next, the influence of the camber angle on the change in the total aerodynamic characteristics was estimated by the dump coefficient of the polar $A$ and the derivatives of the angle of attack of the lift force $C_{L}{ }^{\alpha}$, longitudinal $m_{z}{ }^{\alpha}$ and bending moments $m_{3 \Gamma}{ }^{\alpha}$ (Fig. 6). The coefficient of the longitudinal moment derivative with respect to the angle of attack is calculated with respect to the leading edge of the wing, and the coefficient of the bending moment derivative is calculated with respect to the wing axis of symmetry. An increase in the derivative $m_{3 \Gamma}{ }^{\alpha}$ in the range $\theta=0 \ldots 90^{\circ}$ is due to an increase in the span (shoulder of the resulting aerodynamic force). In the range $\theta=90 \ldots 140^{\circ}$, the growth of the derivative $m_{3 \Gamma}{ }^{\alpha}$ is due to an increase in the load on the WD due to the effect of increased pressure under the wing. The growth of the derivative $m_{z}{ }^{\alpha}$ is due to an increase in the load in the region of the trailing edge of the wing and the rear part of the WD in the range $\theta=0 \ldots 140^{\circ}$. 

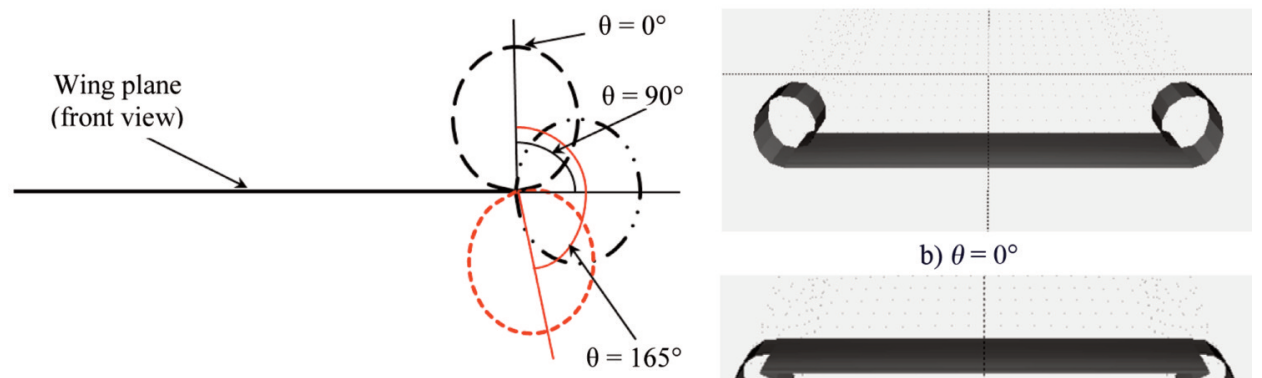

b) $\theta=0^{\circ}$

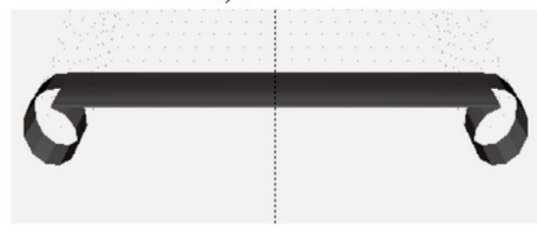

a) camber angle $\theta$

c) $\theta=165^{\circ}$

Fig. 4. Explanation of the WD camber angle $\theta$

a) camber angle $\theta$ reference chart ; b) wing model diagram with WD with camber angle $\theta=0^{\circ}$;

c) wing model diagram with WD with camber angle $\theta=165^{\circ}$.

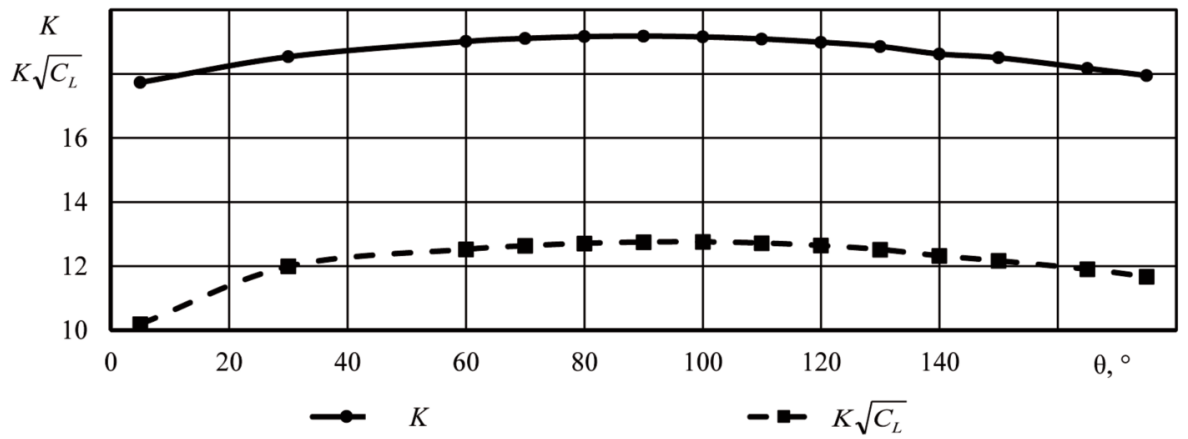

Fig. 5. Dependence of the lift drag ratio $K$ and the aerodynamic criterion $K \sqrt{C_{L}}$ of the 'wing - WD' layout on the camber angle $\theta$ at $\operatorname{Re}=2.1 \times 10^{5}$.

The derivative $C_{L}{ }^{\alpha}$ grows more intensively up to $\theta \approx 70^{\circ}$, then slows down with increasing $\theta$. This is due to the separation of the surfaces of the wing and the WD and a decrease in the flow slope on the main wing. At $\theta>130^{\circ}$, the opposite process occurs. The front part of the WD approaches the lower surface of the wing and creates less lift, negatively affecting the wing and decreasing the total lift of the layout. The dump ratio of polar $A$ has a minimum in the region of $\theta=90^{\circ}$, due to the largest configuration range. From the point of view of providing a minimum inductive resistance, this camber angle is advantageous.

The influence of the area and the relative radius of the WD was investigated jointly, since when the radius changes, the area changes (with other parameters being equal). The area and radius of the WD are parameters that affect the profile drag of the layout due to the introduction and change of additional area into the flow, and the inductive resistance due to the variation in span and elongation of the layout. Our presented results are for a Reynolds number of $2.1 \times 10^{5}$ determined by the length of the wing chord, with the following characteristics of the wing model: constriction $\eta_{\mathrm{WD}}=1$, wing elongation $\lambda_{\text {кр }}=4$, wing profile NACA 23012. Geometric characteristics of the spiroid WD were as follows: root chord $b_{O \mathrm{WD}}=$ $b_{w} / 2$, taper ratio $\eta_{\mathrm{WD}}=1$. The aerodynamic characteristics dependences are given on the relative radius $\bar{r}=r / b_{k}=0.05 \ldots 0.2$. 
The effect on the aerodynamic characteristics was determined for the forward and reverse spiroids (Fig. 7). The difference between spiroids lies in the direction of the loop. When testing a wing model with reverse WD during visualization of the flow by the tuft method, a premature separation of the flow from the upper surfaces of the docking of the wing with the WD and the front part of the WD was found. Further study of reverse WD was discontinued.

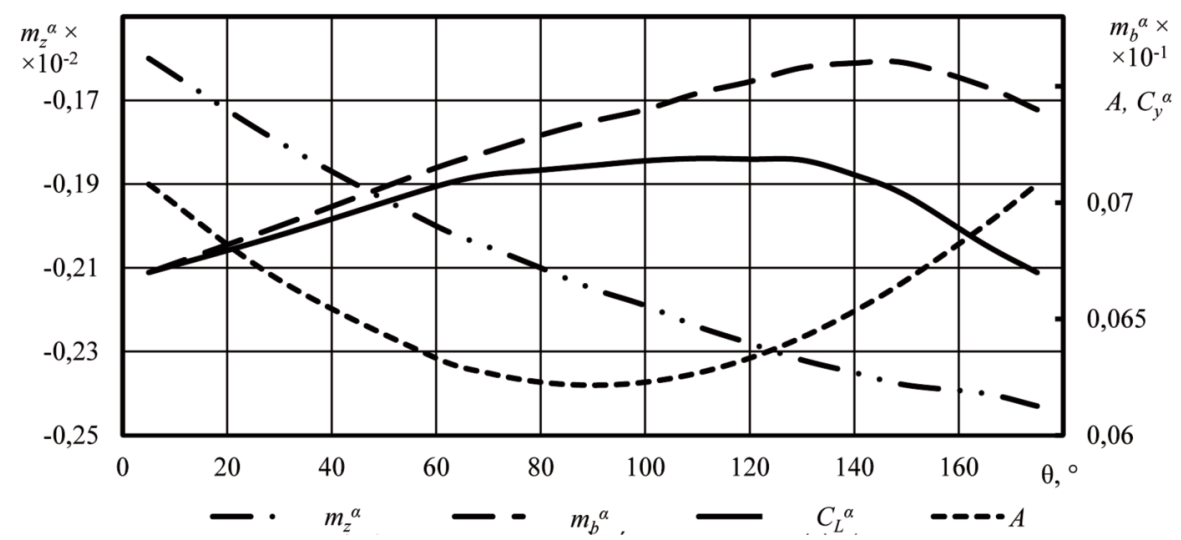

Fig. 6. Dependences of the 'wing - WD' layout's aerodynamic characteristics on the camber angle of the spiroid WD.

The application of spiroid WDs and increasing their area increases the lift coefficient and the polars have a larger gradient (Fig. 8). This is due to an increase in the loading of the final sections, a change in the velocity field behind the wing [24], and the dump coefficient of the polar $A$.

To determine the influence of the area and radius of the spiroid on the lift drag ratio, the dependence $K(\bar{r})$ (Fig. 9) and the gain in the lift drag ratio depending on the relative radius of the spiroid (Table 1) are given for different values of the lift coefficient. At small values of $C_{L} \leq 0.5$ (small angles of attack), when the intensity of the final vortices is small, the establishment of the WD leads to a decrease in the lift drag ratio of the 'wing - WD' layout. A positive effect from the establishment of the WD at small angles of attack is observed at $\bar{r} \geq 0.1$. At $C_{L} \geq 0.6$, an increase in lift drag ratio is observed over the entire range of $\bar{r}$.
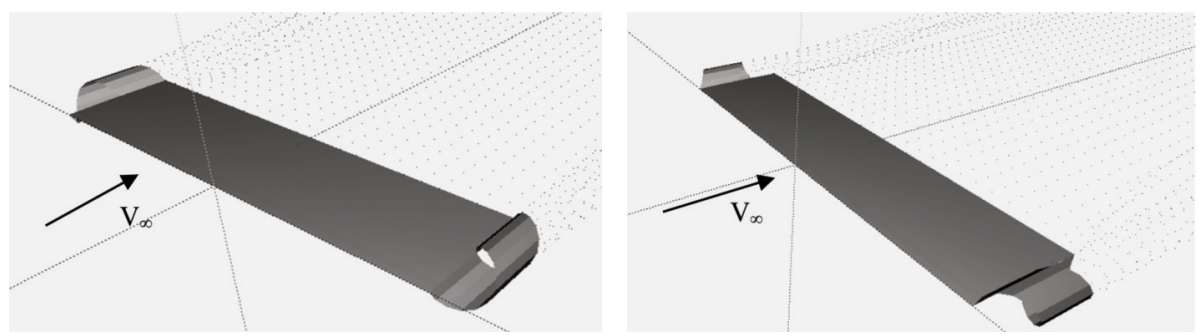

a) isometric view of wing model with different direction spiroids

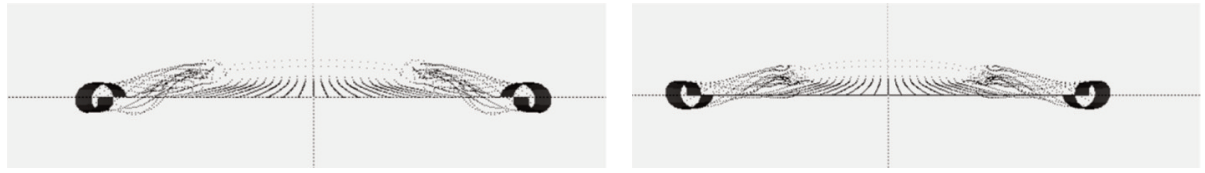

b) front view of a wing model with different direction spiroids

Fig. 7. Computational models of wings with a straight (left) and reverse spiroid (right). 


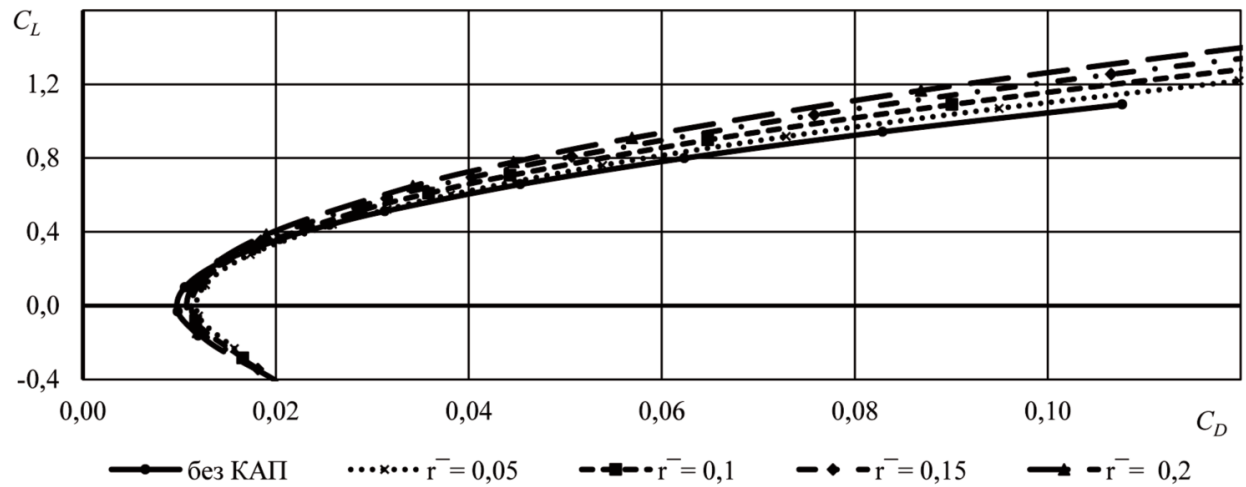

Fig. 8. Comparison of the $C_{L}\left(C_{D}\right)$ dependences for wings with a spiroid WD with different $\bar{r}$ and wings without $\mathrm{WD}\left(\operatorname{Re}=2.1 \times 10^{5}\right)$.

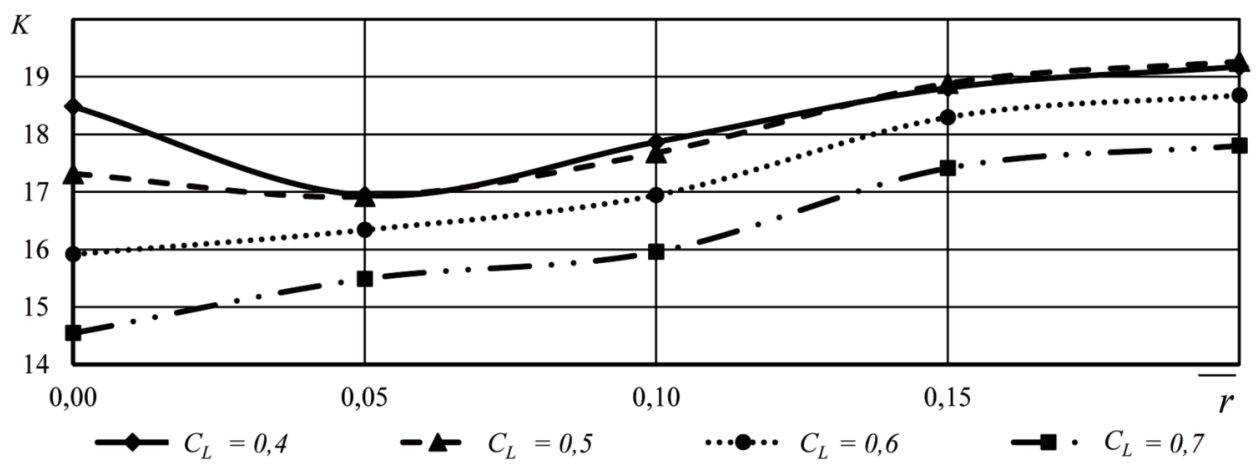

Fig. 9. Comparison of the $K(\bar{r})$ dependences for wings with a spiroid WD at different $C_{L}, \operatorname{Re}=2.1 \times 10^{5}$ ( 0 on the abscissa corresponds to a wing without WD).

Table 1 . The gain in lift drag ratio at $\mathrm{Re}=2.1 \times 10^{5}$ for $\mathrm{WD}$ with different relative radius in comparison with a wing without WD.

\begin{tabular}{|c|c|c|c|c|}
\hline $\bar{r}$ & 0.4 & 0.5 & 0.6 & 0.7 \\
\hline 0.05 & $-8.34 \%$ & $-2.29 \%$ & $2.66 \%$ & $6.47 \%$ \\
\hline 0.10 & $-3.34 \%$ & $2.1 \%$ & $6.47 \%$ & $9.69 \%$ \\
\hline 0.15 & $1.75 \%$ & $9.06 \%$ & $14.96 \%$ & $19.71 \%$ \\
\hline 0.20 & $3.74 \%$ & $11.27 \%$ & $17.37 \%$ & $22.38 \%$ \\
\hline
\end{tabular}

The effect of constriction of spiroid WD was investigated on a model of a rectangular wing with an elongation $\lambda=4$. The constriction of the spiroid $\eta_{\mathrm{WD}}$ is the ratio of the spiroid root chord to the spiroid terminal chord. The study was carried out for $\eta_{\mathrm{WD}}$ in the range from 0.5 to 5 with constant spiroid area and total area of the 'wing - WD' layout. An example of a spiroid of different constriction is shown in Fig. 10. 
The taper ratio of the WD affects the distribution of the load in the final sections of the wing and the WD; there was no significant effect on the total aerodynamic characteristics. In the case when the trailing edge of the WD front part coincides with the leading edge of the WD trailing part at the junction with the wing, the change in the constriction does not cause significant changes in the load distribution. As the constriction increases, the wing area to which the WD adjoins is slightly loaded.
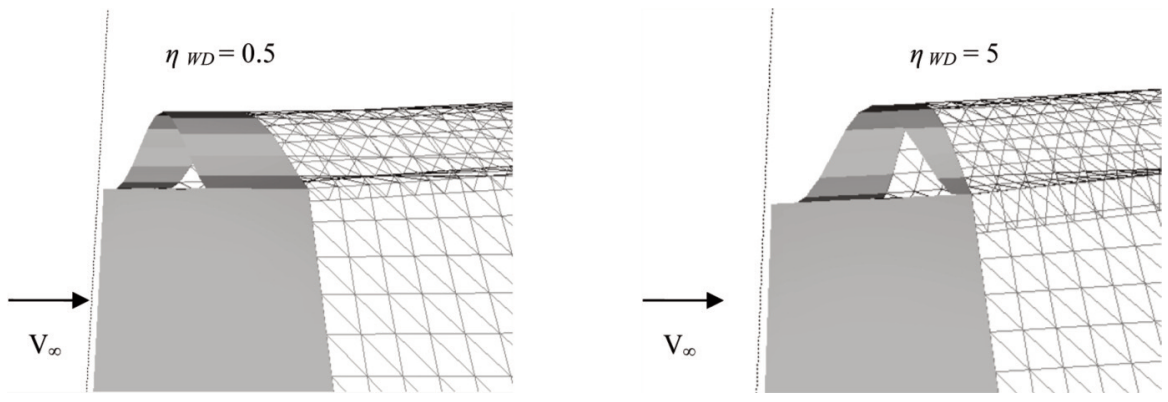

Fig. 10. Spiroid WD of different constriction.

Of practical interest is the case when the position of the root and terminal chords is fixed and the WD taper ratio changes. The chord position is fixed relative to the front and back points of the wing chord. In this case, depending on $\eta_{\mathrm{WD}}$, there is a change in the load distribution over the surface of the 'wing - WD' layout (Fig. 11). To ensure favorable pressure gradients over the surface of the 'wing - WD' layout and to prevent flow separation, it is proposed to impose restrictions on the normal force in the sections of the wing and WD docking. The constraint is $C_{n W D}^{\prime}{ }_{n W} C_{L w}^{\prime}$. Fig. 11 shows the distribution of the normal force $C_{n}^{\prime}$ in the WD sections along the spiroid sweep. When $\eta_{\mathrm{WD}}=1$, the load along the WD is distributed more evenly between the front and rear parts. With an increase in the taper ratio, the zone of final flows increases and the local angle of attack of the WD changes, which leads to loading of the spiroid sections, which are located near the wing trailing edge.

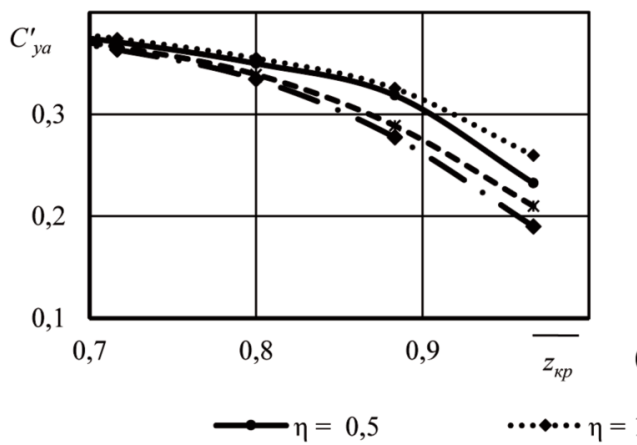

a) distribution of lift along the wingspan

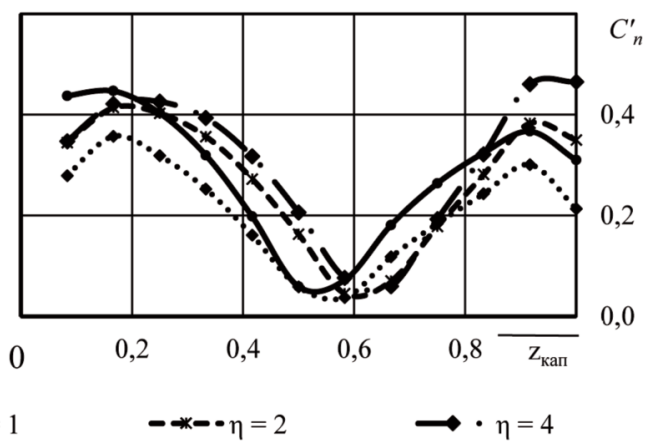

b) the normal force distribution in the sections of the WD swep

Fig. 11. Influence of the spiroid constriction on the distributed aerodynamic characteristics of the wing and the WD.

Our study of the spiroid pitch $\xi$ influence (Fig. 12) was carried out on a model of a layout with a rectangular wing with an aspect ratio of $\lambda=5.12$ with NACA 23012 profile. Spiroid WD selected with the following parameters $\bar{r}=0.1, \eta_{\mathrm{WD}}=3, \theta=90^{\circ}$. The study was carried out up to the case when 
the trailing edges of the wing and the WD are aligned. The spiroid pitch is a parameter that mainly influences the distribution of the load along the WD and in the final sections of the wing.

When the spiroid pitch changes, the distribution of the lift along the wing span changes, especially in the final sections (Fig. 13). At a value $\xi=20 \%$, the final sections of the wing are loaded more, since the WD position provides more overlap of intense final flows zone.

The distribution of the normal force along the WD sweep is shown in Fig. 13b. The spiroid pitch significantly affects the distribution of the normal force in the WD sections, and this influence is determined by the wing caused flow slope and by the aerodynamic trail from the WD. It should be noted that the magnitude of the normal and lift force significantly depends on the section of the WD.
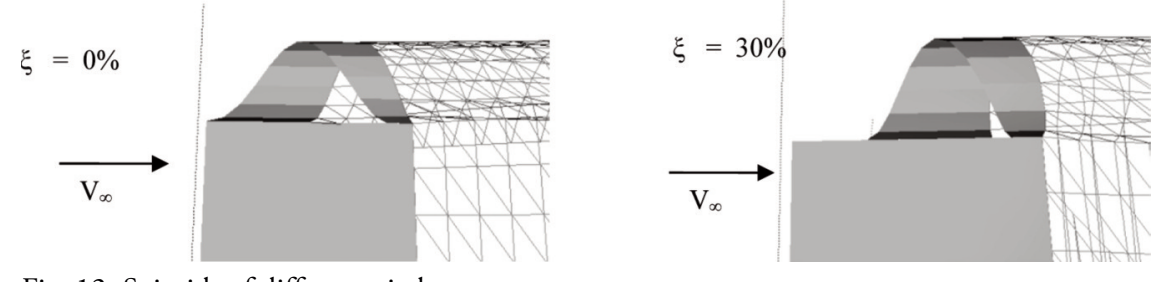

Fig. 12. Spiroids of different pitch.

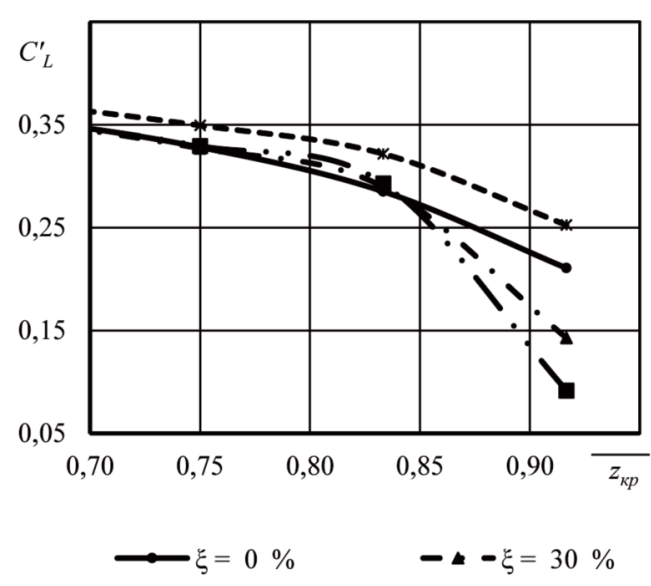

a) lift distribution along the wingspan

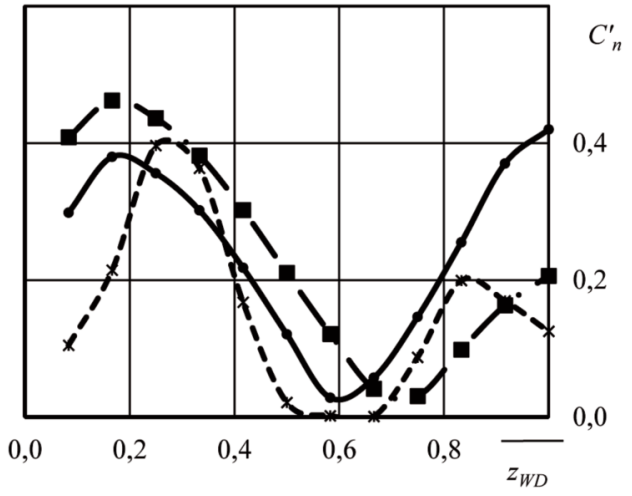

$-*-\cdot \xi=20 \% \quad \longrightarrow \cdot \xi=50 \%$

b) normal force distribution in the sections of the WD sweep

Fig. 13. Influence of the spiroid pitch on the distributed aerodynamic characteristics of the wing and WD.

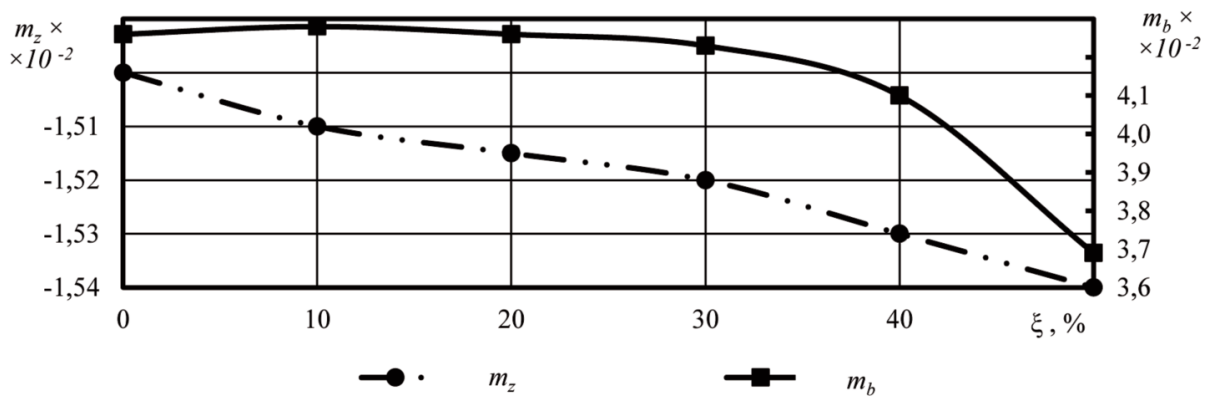

Fig. 14. Dependence of the longitudinal moment coefficient and the bending moment coefficient on the spiroid pitch. 
Changes in the bending moment $m_{b}$ and longitudinal moment $m_{z}$ are shown in Fig. 14. The bending moment, due to the redistribution of the load over the WD and the end sections, is almost unchanged, only with an increase in the spiroid pitch and a decrease in $C_{L}^{\prime}$ of the end sections it decreases.

\section{DISCUSSION OF RESULTS}

The application of spiroid WDs and changes in their geometric parameters affect the flow structure around the end of the wing, which leads to a change in the velocity field and load distribution over the body surface. By changing the camber angle, it is possible to achieve large values of the aerodynamic criteria $K$ and $K \sqrt{C_{L}}$. At an angle of attack of $5^{\circ}$, the value of $K$ can vary within $7.5 \%$ of the maximum value $K_{\max }$, and for $K \sqrt{C_{L}}$ the change is $20.1 \%$ of the maximum value. This is due to the influence of the position of WD and wing surfaces. When $\theta$ is close to 0 , a significant part of the WD is above the wing, reducing the pressure drop across the main wing. When $\theta$ is close to 180 , overflow occurs in the wing front part, generates a vortex, and this causes a flow bevel in front of the wing, generally worsening the distribution of lift by deviation from the elliptical distribution. The best lift distribution is associated with a $90^{\circ}$ camber angle. In this case, the WD wing has the greatest aspect ratio. Verticals formed at the junction of the wing with the WD prevent pressure equalization and reduce the flow slope on the main wing. The presence of shallow localities around the minimum of the polar dump coefficient and the maximum of the lift coefficient derivative, lift drag ratio and aerodynamic criterion $K \sqrt{C_{L}}$ in practice make it possible to use a wide range of camber angles to provide lower moments or more desirable load distribution over the surface of the layout without significant changes in its inductive resistance and bearing properties.

The dependence of aerodynamic characteristics on the relative radius (spiroid area) demonstrates that the WD positive influence is present at $\bar{r}>0.05$ and in a certain range of angles of attack. Analysis of the polar type I of wings without WD and the 'wing - WD' layout allows us to conclude that at low lift values, the wing without WD has the least resistance, and with an increase in $C_{L}$, a wing with large WD has an advantage, since the proportion of inductive drag in the frontal resistance of 'wing - WD' layout increases. In spite of an increase in drag with an increase $\bar{r}$ and $S_{\mathrm{WD}}$, due to the change in the coefficient $A$ of the dependences $C_{L}\left(C_{D}\right)$, the 'wing - WD' layout has a greater gradient. This is explained by the fact that, at small values of the spiroid relative radius, a concentrated vortex continues to form [24] and causes a rather strong flow bevel on the main wing. Also, the WD adding its own profile resistance leads to a deterioration in the lift drag ratio of the layout. With increasing WD, the final vortex is removed from the wing surface and is replaced by two less intense vortices. A change in the flow structure causes a change in the inductive resistance of the 'wing - WD' layout, which affects the lift drag ratio value. Thus, with an increase in the proportion of inductive resistance (intensity of final vortices), the gain in inductive resistance begins to prevail over the WD profile resistance. However, to ensure gain in a wide range of angles of attack, it is necessary to ensure the value of the relative radius $\bar{r} \geq 0.1$. At the same time, an increase in the radius of the spiroid may have limitations in terms of ensuring the rigidity and structure strength.

The constriction and spiroid pitch parameters affect the distribution of the load over the wing surface and the WD. A more uniform distribution of pressure over the wing surface and the spiroid WD is ensured at the maximum overlap of the wing end part by the spiroid WD, that is, at $\eta_{\mathrm{WD}}=1$, and at $\eta_{\mathrm{WD}}=3$, the spiroid pitch should be $\xi \leq 20 \%$. When $\eta_{\mathrm{WD}} \neq 1$, the distance between the parts of the WD increases and the zone in which the pressure leveling on the wing surfaces is possible increases. In this case, an additional flow bevel is generated and this flow bevel continues to increase as the spiroid constriction increases. This leads to decreased load on the wing ends. 


\section{CONCLUSIONS}

1. Our efforts to model the influence of the geometric parameters of a spiroid WD on a wing's aerodynamic characteristics, as reported herein, enabled us to identify values of the geometric parameters of a spiroid WD which provide positive aerodynamic interference when assembled on the wing. This makes it possible to substantiate the choice of the WD parameters in order to ensure the maximum value of the aerodynamic criteria for wings with a spiroid WD. An increase in the relative radius and area of the WD increases the lift drag ratio of the wing with the WD due to a decrease in the final flows and the intensity of the final vortices, which will make it possible to obtain a longer range and duration of UAV flight. With increasing lift coefficient, the gain in the lift drag ratio of the wing layout with the WD increases due to an increase in the proportion of inductive drag. At $\operatorname{Re}=2.1 \times 10^{5}$ for a rectangular wing with an aspect ratio of $\lambda=5.12$ equipped with a spiroid WD $\bar{r}=0.15$, the quality gain is almost $10 \%$ at $C_{L}=0.5$, and at $C_{L}=0.7$ it is almost $20 \%$ compared to a wing without WD.

2. We found that the positive WD influence is present at $\bar{r}>0.05$ and in a certain range of angles of attack. At small values of the spiroid relative radius, a concentrated vortex continues to form and causes a rather strong flow bevel on the main wing. Also, the WD adding its own profile resistance leads to a deterioration in the lift drag ratio of the layout. With an increase in WD, the final vortex is removed from the wing surface and is replaced by two less intense vortices.

3. We found that a change in the camber angle provides an increase in the derivative of the lift coefficient with respect to the angle of attack in the range from $\theta=0^{\circ}$ to $\theta=130^{\circ}$, and the most intense growth is up to the camber angle to $\theta=60^{\circ}$. Maximum load-bearing properties are achieved at $\theta=130^{\circ}$. In this case, the derivatives of the coefficients of the bending and longitudinal moments with respect to the angle of attack increase monotonically to $\theta=140^{\circ}$.

4. Our findings indicate that a change in the camber angle of the WD makes it possible to increase the lift drag ratio of the layout up to $7.5 \%$ at $\theta=90^{\circ}$ as compared to $\theta=0^{\circ}$ at the Reynolds number $\operatorname{Re}=2.1 \times 10^{5}$, while the polar rollback coefficient has a minimum. From the point of view of ensuring maximum lift drag ratio and minimum inductive drag, the angle $\theta=90^{\circ}$ is the most advantageous.

5. By varying the pitch and taper ratio of the spiroid, it is possible to achieve a more favorable distribution of pressure gradients over the surface of the wing and WD, to prevent stall flows and reduce the profile resistance of the layout. Analysis of the pitch and taper ratio of the spiroid on the aerodynamic characteristics supports the conclusion that ensuring the minimum size along the wing chord between the trailing edge of the front part of the WD and the leading edge of the back part of the WD reduces overflows in the wing terminal part. One way to reduce the distance between the WD edges is by root sagging on the back of the WD.

6. When designing a wing with a WD, it is necessary to take into account that the total effect of the application of the WD provides not only an increase in lift and a decrease in inductive resistance, but also a change in bending and longitudinal moments. We anticipate that further studies will identify the influence of the WD on the stability and controllability of the UAV.

7. Since a rectangular wing has a circulation distribution close to elliptical, which corresponds to the minimum inductive resistance, the positive effect on the wing aerodynamic characteristics will increase with increasing sweep and taper ratio of the output wings. 


\section{REFERENCES}

[1] Ovchinnikova, N. G. \& Medvedkov, D. A., 2019, "Primenenie bespilotnyh letatel'nyh apparatov dlja vedenija zemleustrojstva, kadastra i gradostroitel'stva” [The use of unmanned aerial vehicles for land management, cadastre and urban planning], Economy and Ecology of Territorial Formations, 3(1), 98-108. https://doi.org/10.23947/2413-1474-2019-3-1-98-108.

[2] Fedorov L. P. \& Mikhailov Yu.S., 2013, "Opredelenie optimal'nyh rezhimov krejserskogo poleta vysotnogo bespilotnogo letatel'nogo apparat" [Determination of the optimal modes of cruise flight of a high-altitude unmanned aerial vehicle], Scientific Bulletin of MSTU GA, 188, 72-76.

[3] Turkin, I.K. \& Trokhov, D.A. 2015, "Formirovanie oblika vysotnogo bespilotnogo letatel'nogo apparata vozdushnoj razvedki v zadachah poiska" [Formation of the appearance of a high-altitude unmanned aerial reconnaissance aircraft in search tasks], Scientific Bulletin of MSTU GA, 221, 106-114.

[4] Lukyanov O.E., Ostrovoy A.V., Mendes Soto M.A., Klimov E.A., \& Shakhov V.G., 2018, "Osobennosti aerodinamicheskih harakteristik bespilotnyh letatel'nyh apparatov s krylom bol'shogo udlinenia" [Features of the aerodynamic characteristics of unmanned aerial vehicles with a high aspect ratio wing], Scientific Bulletin of MSTU GA, 21(1), 30-39. https://doi.org/10.26467/20790619-2018-21-1-30-39.

[5] Bezuevsky, A., 2019. Osobennosti harakteristik staticheskoj i dinamicheskoj aerouprugosti letatel'nyh apparatov s krylom bol'shogo udlinenia. [Features of the Characteristics of Static and Dynamic Aeroelasticity of Aircraft With High Aspect Ratio Wings]. Ph.D. thesis.

http://www.tsagi.ru/upload/iblock/aa1/ aa1e878d12d7492af8d5dce77a494993.pdf

[6] Marqués, P. and Da Ronch, A., Advanced UAV Aerodynamics, Flight Stability and Control: Novel Concepts, Theory and Applications, 2017, First Edition, John Wiley \& Sons Ltd.

[7] Djojodihardjo, H., 2011, "Review on development and recent patents on trailing vortices alleviation", Recent Patents on Mechanical Engineering, 4, 41-48.

[8] Abbas, A., Vicente, J., \& Valero, E, 2013, Aerodynamic technologies to improve aircraft performance. Aerospace Science and Technology, 28, 100-132.

[9] Gratzer, L., 1991. Spiroid-Tipped Wing Pat. 5.102.068, cod. US005102068A

[10] Nazarinia, M., Soltani, M. R., \& Ghorb K., 2006, "Experimental study of vortex shapes behind a wing equipped with different winglets", JAST, 1(3), 1-15.

[11] Suhail Mostafa, Shyam Bose, Archana Nair, Mansoor Abdul Raheem, Thasneem Majeed, Atiqur Mohammed \& Young Kim, 2014, "A parametric investigation of non-circular spiroid winglets", EPJ Web of Conferences, 67(02077), 1-6. https://doi.org/10.1051/epjconf/20146702077.

[12] Manikandan, G., Rajashree, V. \& Gràcia, S., 2017, "Design and performance analysis of spiroid winglet with normal wing”, Imperial Journal of Interdisciplinary Research, 3, 1-12.

[13] Raj W. N. \& Thomas, T., 2015, “Design and Analysis of Spiroid Winglet”, International Journal of Innovative Research in Science, Engineering and Technology, 4, 1139-1147.

[14] Guerrero, J.E., Maestro, D., \& Bottaro, A., 2014, "Biomimetic spiroid winglets for lift and drag control”, Comptes Rendus Mecanique. 340, 67-80. 10.1016/j.crme.2011.11.007.

[15] Samuel, M. \& Parvathy, R., 2019, "A review of winglets on tip vortex, drag and airfoil geometry", Journal of Advanced Research in Fluid Mechanics and Thermal Sciences, 63, 218-237.

[16] Hantrais-Gervois, J.-L., Grenon, R., Mann, A., \& Buscher, A., 2009, “Downward pointing winglet design and assessment within the M-DAW research project", The Aeronautical Journal, 113(1142), 221-232.

[17] Hammer, P. Altman, A. \& Eastep, F., 2014, "Validation of a discrete vortex method for low Reynolds number unsteady flows", AIAA Journal, 3(52), 643-649.

[18] Katz, J., and Plotkin, A., 2001, Low Speed Aerodynamics, 2nd ed., Cambridge Univ. Press, Cambridge, England, U.K. 
[19] Gudmundsson, Sh., 2014, General Aviation Aircraft Design, Chapter 15 - Aircraft Drag Analysis, Butterworth-Heinemann, pp. 661-760. https://doi.org/10.1016/B978-0-12-397308-5.00015-5.

[20] Cameron, T., Yarin, A. \& Foss J., 2007, Springer Handbook of Experimental Fluid Mechanics, Verlag Berlin Heidelberg.

[21] Kuzenkov, V. K., Mikhailova, N. P. \& Repik E. U., 1984, “Ob eksperimental'nom opredelenii profil'nogo soprotivlenia metodom impul'sov" [On the experimental determination of the profile resistance by the pulse method], TsAGI Scientific Notes, 1(15), 110-114.

[22] Ukrainets, Ye.O., Hlushchenko, P.A. \& Spirkin V. 2918, "Viznachenna znachen' kriteriïv doskonalosti aerodinamichnoï trubi pri tehnichnij pidgotovci aerodinamichnogo eksperimentu" [Determination of values of criteria of perfection of a wind tunnel at technical preparation of aerodynamic experiment], Weapons systems and Military Equipment, 3(55), 100-107. https://doi.org/10.30748/soivt.2018.55.14.

[23] Hizhnyak, A.S., Glushenko, P.A. \& Spirkin, Ye.V., 2016, “Metodika aerodinamichnih viprobuvan’ modelej vinišuvachiv z imitacieû dviguniv" [Methods of aerodynamic tests of fighter models with engine simulation], Science and Technology of the Air Force of the Armed Forces of Ukraine, 2, 47-51.

[24] Popov, V., Loginov, V., Ukrainets, Ye., Shmyrov, V., Steshenko P. \& Hlushchenko, P., 2020, "Improving aircraft fuel efficiency by using the adaptive wing and winglets", Eastern-European Journal of Enterprise Technologies, 2, 1(104), 51-59.

http://doi.org/10.15587/1729-4061.2020.200664

\title{
CHARAKTERYSTYKA AERODYNAMICZNA SKRZYDŁA PROSTEGO Z URZĄDZENIEM SPIROIDALNYM NA KOŃCÓWCE SKRZYDŁA
}

\begin{abstract}
Abstrakt
Spiroidalne końcówki skrzydeł (wingtip devices, WD) stanowią obiecującą metodę na poprawę współczynnika oporu aerodynamicznego bezzałogowych statków powietrznych (UAVs). Jednak z drugiej strony mogą prowadzić do negatywnej interferencji aerodynamicznej skrzydła z spiroidalną końcówką i pogorszenia charakterystyk aerodynamicznych w porównaniu do skrzydła bez końcówki. Określenie wpływu parametrów geometrycznych spiroidalnej końcówki na charakterystyki aerodynamiczne skrzydła pozostaje jednak nadal słabo zbadanym zagadnieniem. W pracy tej zbadano wpływ następujących parametrów geometrycznych na charakterystyki aerodynamiczne skrzydła z WD: powierzchnia, promień, kąt pochylenia, przewężenie i rzut spiroida. Stwierdziliśmy, że pozytywny wpływ WD występuje przy promieniu względnym $\bar{r}>0,05$, jak również przy wzroście współczynnika siły nośnej $C_{L} \mathrm{w}$ wyniku wzrostu udziału oporu indukowanego. Przykładowo, przy liczbie Reynoldsa $\operatorname{Re}=2,1 \times 10^{5}$ dla skrzydła prostokątnego o wydłużeniu $\theta=5,12$ wyposażonego w spiroidalną końcówkę WD $\bar{r}=0,15$ przyrost jakości wynosi przy $C_{L}=0,5$ prawie $10 \%$, a przy $C_{L}=0,7$ prawie $20 \%$ i przy $C_{L}=0,7-$ prawie $20 \%$ w stosunku do skrzydła bez WD. Ponadto stwierdziliśmy, że zmiana kąta pochylenia WD $\theta$ zapewnia wzrost pochodnej współczynnika nośności względem kąta natarcia w zakresie od $\theta=0^{\circ}$ do $\theta=130^{\circ}$. Poprzez zmianę kąta pochylenia możliwe jest zwiększenie doskonałości aerodynamicznej układu do 7,5\% przy $\theta=90^{\circ}$ w stosunku do $\theta=0^{\circ}$ przy liczbie Reynoldsa $\operatorname{Re}=2,1 \times 10^{5}$. Z punktu widzenia zapewnienia maksymalnej doskonałości aerodynamicznej i minimalnego oporu indukowanego kąt $\theta=90^{\circ}$ jest najkorzystniejszy.
\end{abstract}

Słowa kluczowe: spiroidalne końcówki skrzydeł, bezzałogowe statki powietrzne, doskonałość aerodynamiczna, zasięg lotu, długotrwałość lotu, konfiguracja aerodynamiczna 